Volume 9, No.1, January - February 2020

International Journal of Advanced Trends in Computer Science and Engineering

Available Online at http://www.warse.org/IJATCSE/static/pdf/file/ijatcse57912020.pdf

https://doi.org/10.30534/ijatcse/2020/57912020

\title{
Reliability consideration costing method for LIFO Inventory model with Chemical Industry Warehouse
}

\author{
Ajay Singh Yadav ${ }^{1}$, Navyata ${ }^{2}$, Neelam Sharma ${ }^{3}$, Navin Ahlawat ${ }^{4}$, Anupam Swami ${ }^{5}$ \\ ${ }^{1}$ Department of Mathematics, SRM Institute of Science and Technology, Delhi-NCR Campus Ghaziabad, Uttar \\ Pradesh, India., ajay29011984@gmail.com \\ ${ }^{2}$ Research Scholar, Mewar University, Chittorgarh, Rajasthan, singhnavyata25@ gmail.com \\ ${ }^{3}$ Department of Mathematics, KIET, Ghaziabad, Uttar Pradesh, India.,neelam.sharma@kiet.edu \\ ${ }^{4}$ Department of Computer Science, SRM Institute of Science and Technology, Delhi-NCR Campus Ghaziabad, Uttar \\ Pradesh, India., navinahlawat@gmail.com \\ ${ }^{5}$ Department of Mathematics, Government Post Graduate College, Sambhal, Uttar Pradesh, India \\ swami.anupam@gmail.com
}

\begin{abstract}
We propose to subject chemical industry inventory models with reliability requirements for inventories using the LIFO inventory model inventory method and optimize the inventory model with reliability considerations in the chemical industry "supply chain". We specifically effort on determining the active nature of additional inventories and scarcity levels required for inventory models with reliability in the supply chain of the chemical industry, So that the inventory model with overall chemical industry inventory reliability is minimized for inventory management with environmental costs. The complication of the difficultupsurges when additional products and many agents are included in the chemical industry inventory model with reliability.Here we propose an optimization method that uses the LIFO inventory model along with the reliability evaluation method and to dazed the bottleneck in continuing optimal inventory levels of each member of the chemical industry inventory model with reliability management. Good optimization is one of the algorithms. We apply our method to a member of the chemical industry inventory model with reliability.
\end{abstract}

Key words: -Probabilistic tools, Inventory model, deteriorating items, warehouse, LIFO Inventory model and Reliability Consideration costing method

\section{INTRODUCTION}

Inventory management of the chemical industry through weather-resistant chemical products can be described as a "chemical industry inventory management". Chemical abrasives can be used to coordinate production, storage, location, and transportation between participants in the chemical industry to attain the best blend of responsibility and competence for the market. "According to an appraisal of the literature, it's clear that previous studies have particular shortcomings: In the integrated inventory model, the above conditions are rarely associated with the use of chemically offensive items in the control checklist. In addition, minimizing the cost of inventory models in recent years has attracted the attention of some researchers, who, however, only considered one side of the list of the chemical industry, the purchaser or seller side As declaredprior, the current incorporation of equipment is very important to succeed in a competitive market for chemical processing warehouses using chemical degradation products. Unfortunately, market researchers do not have not dealt with this central issue of inventory management in the chemical industry. Some of us may like to eat rice while others like wheat rather than a variety of dishes because our staple crops are readily available when demand is no longer paid but at a higher cost than usual availability. But have we ever wondered where these vegetables, rice or wheat are made? We all know that these food grains are not produced all year round, but we have to eat them every day of the year. So how can farmers continually supply them? We can imagine that they store the grain products in the right place and deliver them at the right time. Yes, we are right Since production takes place at a certain time of the year and in some regions, these food grains need to be systematically stored. In our house we can keep limited supplies for self-consumption, for example. 4$5 \mathrm{~kg}$ of lentils, $20-50 \mathrm{~kg}$ of wheat / rice, and we have to buy it again after a single interval. For this purpose, namely. In order to provide us with the required items when needed, there are certain locations or stores where these items are properly and properly stored in bulk. We need different types of goods in our daily lives. We can buy some of these items in bulk and keep them in our house. Similarly, businessmen also need many types of goods for the business, but some of them are not always available. But they need these items all year round without breaking. Coal is needed throughout the year to produce coal, which is used as a raw material in a power plant (thermal power station). Coal is not available at each location and must be brought to a specific location that takes time to be stored year-round for use when needed. As coal is in demand at the plant, it is a continuous process of generating electricity. Thus, the storage requirement arises for both 
raw materials and finished products (eg electricity). Since storage is an appropriate system for storing goods from the moment of purchase to their actual use or use, sufficient space is needed for storage. When this storage is carried out on a large scale and in a certain way, it is called storage.

\section{RELATED WORKS}

"Yadav and Swami $(1,2)$ " [Introduction an integrated supply chain model for commodity deterioration with a stock-dependent linear demand in a climate of disorder and inflation and a time-varying constraint on a model. the size of the lots of the female stock. "Yadav et al. $(3,4,5,6)$ " \{Introduction of a supply chain inventory model for the expiry of sub-inventory goods at two warehouses and inflation and proposal of an inventory model for the deterioration of two warehouses and items with variable cost and deteriorated. Discuss the green supply chain inventory management analysis for warehouses with storage and environmental cooperation using a genetic algorithm and sustainability performance using a genetic algorithm. Yadav and Kumar (7) showcased supply chain management of electronic components for warehousing in collaboration with the environment and neural networks. Yadav et al. $(8,9,10)$ (investigated the effect of inflation on a two-stock inventory model for commodities that worsened with changing requirements and deficiencies.) Discussed an inventory model inflationary for the deterioration of goods in two warehouse systems and proposed a two-store fuzzy store -Model for nonmerchandise before temporary deterioration of the goods with late payment conditionally authorized. Yadav (11) \{Analysis of Supply Chain Management in Inventory Optimization for Warehouses with Logistics Using the Genetic Algorithm\}.Yadav et al. $(12,13)$ \{Explain the supply chain inventory model for two bearings with optimized soft computing functionality\}. Yadav (14) \{Modeling and Analysis of the Supply Chain Inventory Model with Economic and Two-Delay Load Transfer Problems Using the Genetic Algorithm\}.

\section{ASSUMPTIONS AND NOTATIONS}

1. A single item is considered over a prescribed period $\mathrm{T}$ units of time.

2. The demand rate $D(t)$ at time $t$ is deterministic and taken as a ramp type function of time i.e.

$$
D(t)=e^{-\frac{\beta}{\alpha}\left\{t-\left(t-t_{L}\right) H\left(t-t_{L}\right)\right\}}, \frac{\beta}{\alpha}>0
$$

3. The backlogging rate is $\exp \left(-\lambda^{2} \mathrm{t}\right)$, when inventory is in shortage. The backlogging parameter $\lambda^{2}$ is a "positive constant".

4. The variable "rate of deterioration" in both chemical industry warehouse is taken as $\eta^{2}(\mathrm{t})=\eta^{2} \mathrm{t}$. Where $0<\eta^{2}<<1$ and only applied to on hand inventory.
In addition, the following notations are used throughout this paper:

$\Pi_{w}(\mathrm{t})=$ The inventory level in chemical industry chemical industry warehouse at Any time t.

$\mathrm{W}=$ The capacity of the chemical industry warehouse.

$\mathrm{Q}=$ The ordering quantity per cycle.

$\mathrm{T}=$ Planning horizon .

$\phi^{2}=$ Inflation rate.

$H C_{L}=$ Holding cost per unit per unit time in chemical industry warehouse.

$D C_{L}=$ Deterioration cost per unit.

$L S_{L}=$ Opportunity cost due to lost sales.

$L_{O C}=$ Replenishment cost per order.

CIWTC $=$ Chemical Industry Warehouse Total Cost

\section{FORMULATION AND SOLUTION OF THE}

MODEL

$\frac{d \Pi_{w}(t)}{d t}+\eta^{2}(t) \Pi(t)=-e^{-\frac{\beta}{\alpha} t}, \quad 0 \leq t<t_{L}(1)$

With the boundary condition $\Pi_{w}(0)=0$

The solution of the equation (1) is

$\Pi_{w}(t)=\left\{\left(t_{L}-t\right)-\frac{\beta}{2 \alpha}\left(t_{L}^{2}-t^{2}\right)+\frac{\eta^{2}}{6}\left(t_{1}^{3}-t^{3}\right)\right\} e^{-\eta^{2} t^{2} / 2}$,

$t_{L} \leq t \leq t_{1}(2)$

The total average cost consists of following elements:

(i) Cost of ordering $=O C_{L_{(3)}}$

(ii) Cost of holding (CHR) in chemical industry

warehouse

$C_{H R}=H C_{L}\left[\int_{0}^{t} \Pi_{w}(t) e^{-\phi^{2} t} d t\right]_{(4)}$

(iii) Cost of deteriorated units (CD)

$=D C_{L}\left[\int_{0}^{t} \eta^{2} t \Pi_{w}(t) e^{-\phi^{2} t} d t\right]$ 
(vi) Opportunity cost due to lost sales $\left(\mathrm{C}_{0}\right)$

$=L S_{L} \int_{t_{1}}^{T}\left(1-e^{-\lambda^{2} t}\right) e^{-\frac{\beta}{\alpha}\left(t_{L}\right)} e^{-\phi^{2}\left(t_{1}+t\right)} d t(6)$

Consequently, the total regular cost per unit time of our model is obtained as shadows
$\operatorname{CIWTC}\left(t_{1}, T\right)=\frac{1}{T}$ [Ordering cost + Holding cost in chemical industry warehouse + Deterioration cost + Opportunity cost]

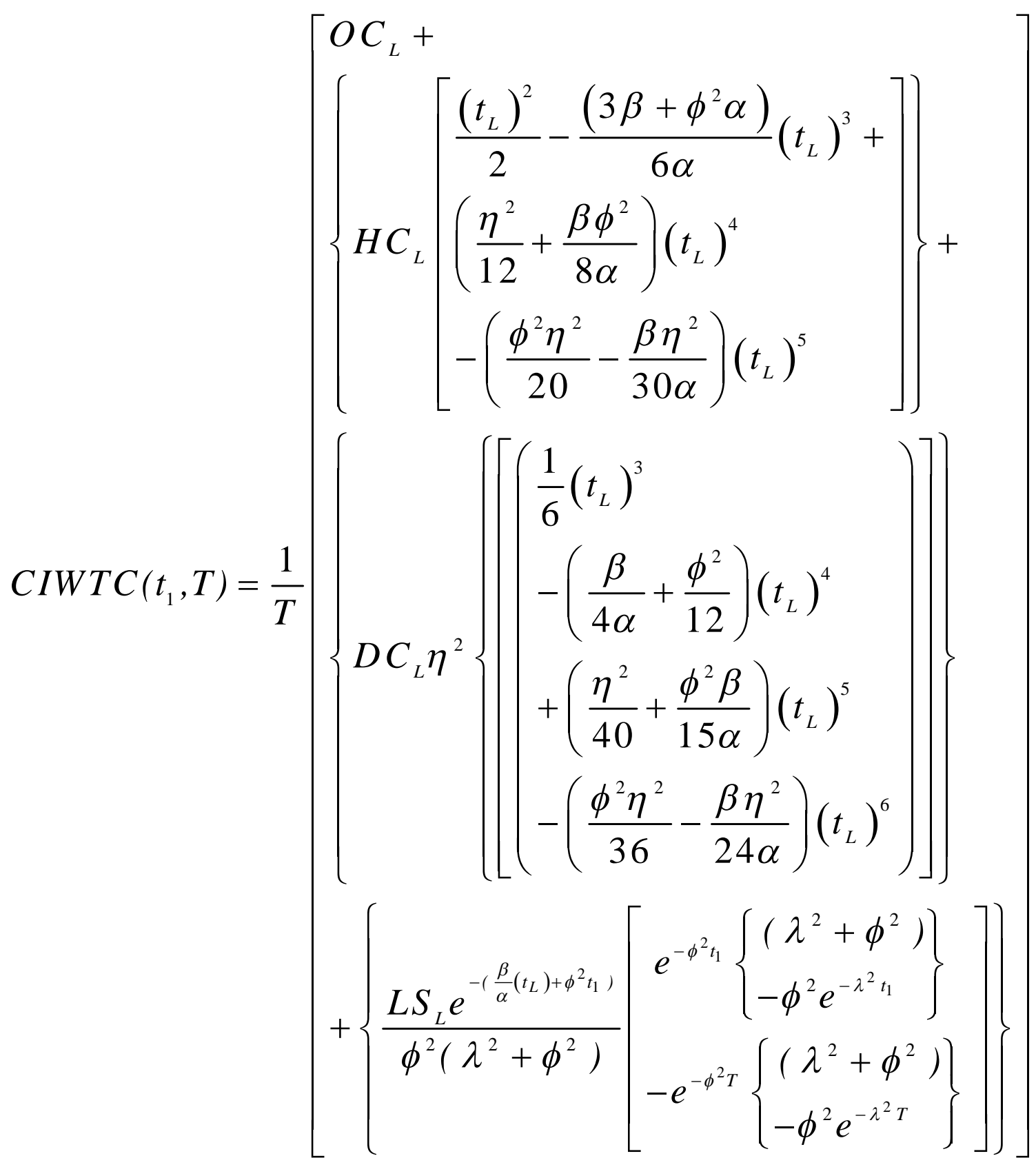




\section{CONTINUOUS RANDOM VARIABLE AND PROBABILITY DENSITY FUNCTION}

\subsection{Continuous Random Variable}

Definition:- A random variable $\mathrm{X}$ with $\mathrm{F}_{\mathrm{X}}($.) as Continuous

Random Variable is called Continuous if there exists a function $\mathrm{f}_{\mathrm{X}}():. R \rightarrow[0, \infty)$ Such that

$$
F_{X}(x)=\int_{-\infty}^{x} f_{X}(t) d t \text { for all } x \in R
$$

The function $\mathrm{f}_{\mathrm{X}}($.$) is called the Probability density function$ of X

\subsection{Probability Density Function}

Definition:-Any functionf $\mathrm{x}_{\mathrm{X}}():. R \rightarrow[0, \infty)$ is said to be a

Probability Density Function if

\section{SENSITIVITY ANALYSIS}

Table:-1 Demand parameter $\beta$

\begin{tabular}{|c|c|c|c|c|c|}
\hline$\beta$ & $\mathrm{T}$ & $C I W T C$ & Mean & Variance & Standard Deviation \\
\hline 752.5 & 782.65 & 7250.53 & 0.416 & 0.806 & 0.997 \\
\hline 754 & 782.57 & 7249.35 & 0.415 & 0.805 & 0.987 \\
\hline 756.7 & 782.55 & 7248.23 & 0.414 & 0.804 & 0.967 \\
\hline 758 & 787.85 & 4248.00 & 0.413 & 0.802 & 0.947 \\
\hline 750.2 & 787.75 & 4247.98 & 0.412 & 0.801 & 0.727 \\
\hline
\end{tabular}

Table:-2 Demand parameter $\alpha$

\begin{tabular}{|c|c|c|c|c|c|}
\hline$\alpha$ & $\mathrm{T}$ & $C I W T C$ & Mean & Variance & Standard Deviation \\
\hline 70.62 & 732.65 & 7380.53 & 0.496 & 0.906 & 0.697 \\
\hline 70.62 & 732.57 & 7379.35 & 0.485 & 0.905 & 0.387 \\
\hline 70.7 & 732.55 & 7368.23 & 0.467 & 0.904 & 0.267 \\
\hline 70.72 & 737.85 & 7358.00 & 0.446 & 0.902 & 0.147 \\
\hline 70.72 & 737.75 & 7347.98 & 0.425 & 0.901 & 0.027 \\
\hline
\end{tabular}


Table:-3 Backlogging parameter $\lambda^{2}$

\begin{tabular}{|c|c|c|c|c|c|}
\hline$\lambda^{2}$ & $\mathrm{~T}$ & CIWTC & Mean & Variance & Standard Deviation \\
\hline 70.43 & 722.65 & 7898.53 & 0.596 & 0.306 & 0.696 \\
\hline 70.49 & 722.57 & 7897.34 & 0.585 & 0.305 & 0.385 \\
\hline 70.53 & 722.55 & 7996.23 & 0.567 & 0.304 & 0.267 \\
\hline 70.55 & 730.85 & 7996.00 & 0.546 & 0.302 & 0.146 \\
\hline 70.54 & 730.75 & 7995.98 & 0.525 & 0.301 & 0.025 \\
\hline
\end{tabular}

Table:-4 Selling price $\left(L S_{L}\right)$

\begin{tabular}{|c|c|c|c|c|c|}
\hline$L S_{L}$ & $\mathrm{~T}$ & $C I W T C$ & Mean & Variance & Standard Deviation \\
\hline 724.5 & 752.65 & 7478.53 & 0.296 & 0.376 & 0.196 \\
\hline 724.9 & 752.57 & 7477.35 & 0.385 & 0.365 & 0.085 \\
\hline 725.0 & 752.55 & 7476.23 & 0.467 & 0.357 & 0.067 \\
\hline 725.2 & 757.85 & 7476.20 & 0.546 & 0.346 & 0.046 \\
\hline 725.9 & 757.75 & 7475.98 & 0.625 & 0.315 & 0.025 \\
\hline
\end{tabular}

Table:-5 Deterioration parameter $\eta^{2}$

\begin{tabular}{|c|c|c|c|c|c|}
\hline$\eta^{2}$ & $\mathrm{~T}$ & CIWTC & Mean & Variance & Standard Deviation \\
\hline 70.00 & 772.65 & 7308.53 & 0.196 & 0.396 & 0.296 \\
\hline 70.62 & 772.57 & 7307.35 & 0.185 & 0.385 & 0.285 \\
\hline 70.7 & 772.55 & 7306.23 & 0.167 & 0.367 & 0.267 \\
\hline 70.72 & 770.85 & 7306.00 & 0.146 & 0.346 & 0.246 \\
\hline 70.74 & 770.75 & 7305.98 & 0.125 & 0.325 & 0.225 \\
\hline
\end{tabular}

\section{CONCLUSION}

Storing chemicals for chemical degradation and stability stocks using the LIFO inventory calculation method and neural networks is an integral part of inventory management in the chemical industry. The new efficient approach is based on the application of the LIFO inventory method, using Bullion's reliability and neural network approach, to optimize inventories in inventory management in the chemical industry for inventory chemical networks. Specifically, we focus on identifying the complexity of forecasting optimal inventory levels and inventory reduction for chemical inventory management to reduce overall chemical inventory costs. Let's focus. We apply our three-tier chemical inventory management methods to inventories of chemical degradation products that have been studied for optimization. The proposed methodology has been implemented and its performance evaluated with MATLAB.

\section{REFERENCES}

1. Yadav, A.S. and Swami, A. (2018)"Integrated Supply Chain Model for Deteriorating Items with Linear Stock Dependent Demand under Imprecise and Inflationary Environment".International Journal Procurement Management, Volume 11 No 6.

https://doi.org/10.1504/IJPM.2018.10016405

2. Yadav, A.S. and Swami, A. (2018)"A partial backlogging production-inventory lot-size model 
with time-varying holding cost and weibulldeterioration".International Journal Procurement Management, Volume 11, No. 5.

3. Yadav, A.S., Swami, A. and Kumar, S. (2018) "A supply chain Inventory Model for decaying Items with Two Ware-House and partial ordering under Inflation". International Journal of Pure and Applied Mathematics, Volume 120 No 6.

4. Yadav, A.S., Swami, A. and Kumar, S. (2018) An Inventory Model for Deteriorating Items with Two warehouses and variable holding Cost.International Journal of Pure and Applied Mathematics, Volume 120 No 6.

5. Yadav, A.S., Swami, A. and Kumar, S. (2018) Inventory of Electronic components model for deteriorating items with warehousing using Genetic Algorithm. International Journal of Pure and Applied Mathematics, Volume 119 No. 16.

6. Yadav, A.S., Johri, M., Singh, J. and Uppal, S. (2018) Analysis of Green Supply Chain Inventory Management for Warehouse With Environmental Collaboration and Sustainability Performance Using Genetic Algorithm. International Journal of Pure and Applied Mathematics, Volume 118 No. 20.

7. Yadav, A.S., and Kumar, S. (2017) Electronic Components Supply Chain Management for Warehouse with Environmental Collaboration \& Neural Networks. International Journal of Pure and Applied Mathematics, Volume 117 No. 17.

8. Yadav, A.S., Taygi, B., Sharma, S. and Swami, A. (2017) Effect of inflation on a two-warehouse inventory model for deteriorating items with time varying demand and shortages.International Journal Procurement Management, Volume 10, No. 6.
9. Yadav, A.S., Mahapatra, R.P., Sharma, S. and Swami, A. (2017) An Inflationary Inventory Model for Deteriorating items under Two Storage Systems.International Journal of Economic Research, Volume 14 No.9.

10. Yadav, A.S., Sharma, S. and Swami, A. (2017) A Fuzzy Based Two-Warehouse Inventory Model For Non instantaneous Deteriorating Items With Conditionally Permissible Delay In Payment.International Journal of Control Theory And Applications, Volume 10 No.11.

11. Yadav, A.S., (2017) Analysis of Supply Chain Management In Inventory Optimization For Warehouse With Logistics Using Genetic Algorithm.International Journal of Control Theory And Applications, Volume 10 No.10.

12. Yadav, A.S., Swami, A., Kher, G. and Kumar, S. (2017) Supply Chain Inventory Model for Two Warehouses with Soft Computing Optimization.International Journal of Applied Business and Economic Research Volume 15 No 4.

13. Yadav, A.S., Mishra, R., Kumar, S. and Yadav, S. (2016) Multi Objective Optimization for Electronic Component Inventory Model \& Deteriorating Items with Two-warehouse using Genetic Algorithm.International Journal of Control Theory and applications, Volume 9 No.2.

14. Yadav, A.S., (2017) Modeling and Analysis of Supply Chain Inventory Model with twowarehouses and Economic Load Dispatch Problem Using Genetic Algorithm International Journal of Engineering and Technology (IJET) Volume 9 No 1.

https://doi.org/10.21817/ijet/2017/v9i1/170901405

15. Kumar. R (2008) Probability and mathematical statistics (book). Vardhman publication 